\title{
Perancangan Pengukuran Akurasi Jarak Menggunakan Phantom Silicone Pada Kontrol Kualitas Ultrasonografi Dengan Teknik Komputasi
}

\author{
Dwi Pangestuti ${ }^{1,}{ }^{*}$, Giner Maslebu ${ }^{1}$, Suryasatriya Trihandaru ${ }^{1}$ \\ ${ }^{1}$ Jurusan Fisika, Fakultas Sains dan Matematika, Universitas Kristen Satya Wacana, Salatiga, Jawa Tengah \\ 50711 \\ "email korespondensi: $\underline{\text { dwip37.dp@gmail.com }}$
}

\begin{abstract}
ABSTRAK
Penelitian ini bertujuan untuk melakukan uji kualitas USG dengan melakukan komputasi perhitungan jarak pada citra USG dan melakukan analisis pengukuran jarak objek phantom silicon dengan mengubah variasi frekuensi dan kedalaman. Variasi kedalaman rata-rata jarak sebenarnya objek 1, 2, 3 pada phantom sebesar $1 \mathrm{~cm}, 2 \mathrm{~cm}$, dan 3 $\mathrm{cm}$ dari permukaan. Pada frekuensi 3,5 MHz, nilai kedalaman visualisasi objek 1 didapatkan hasil jarak rata-rata komputasi sebesar $1,0039 \mathrm{~cm}$ dengan nilai deviasi 0,0814 sehingga nilai kesalahan jarak sebenarnya sebesar 0,39\%. Nilai kedalaman visualisasi objek 2 didapatkan hasil jarak rata-rata komputasi sebesar 1,4897 cm dengan nilai deviasi sebesar 0,0099 sehingga nilai kesalahan jarak sebenarnya sebesar 25,51\%. Nilai visualisasi kedalaman obyek yang memiliki jarak rata-rata komputasi sebesar $3,3336 \mathrm{~cm}$ dengan nilai deviasi 0,1191 sehingga nilai kesalahan jarak rill sebesar 11,12\%. Pada frekuensi tetap 4,5 MHz, nilai kedalaman visualisasi objek 1 didapatkan hasil jarak rata-rata komputasi sebesar 0,9931 cm dengan nilai deviasi 0,05 sehingga nilai kesalahan jarak sebenarnya sebesar 0,69\%. Nilai visualisasi kedalaman objek 2 didapatkan hasil jarak rata-rata komputasi sebesar 1,6584 cm dengan nilai deviasi sebesar 0,0573 sehingga nilai kesalahan jarak sebenarnya sebesar 17,08\%. Nilai visualisasi kedalaman objek 3 yang memiliki jarak rata-rata komputasi sebesar $3,4943 \mathrm{~cm}$ dengan nilai deviasi 0,0741 sehingga nilai kesalahan jarak sebenarnya sebesar 16.47\%. Dari semua hasil komponen uji menunjukkan perhitungan jarak pada citra pesawat USG bisa dilakukan dengan menggunakan perangkat lunak komputer.
\end{abstract}

Kata-kata kunci: akurasi jarak; Phantom Silicone; USG

\section{PENDAHULUAN}

Pemanfaatan gelombang bunyi semakin berkembang seiring dengan kemajuan teknologi saat ini. Salah satu bentuknya adalah untuk melihat organ dalam tubuh manusia dengan peralatan medis USG. USG yang menggunakan prinsip kerja gelombang bunyi sebagai radiasi non-pengion dinyatakan aman, akurat dan efektif untuk mengetahui kelainan pada organ pasien yang diperiksa. Sehingga, modalitas ini banyak dipergunakan dokter untuk membantu diagnosa pasien. Aliran gelombang suara ditentukan oleh kepadatan medium yang dilalui. Hal ini dipengaruhi oleh absorbsi gelombang suara oleh medium. Refleksi gelombang yang dibentuk merupakan hasil pertemuan dua media dengan impedansi akustik yang berbeda (Munawar, W, \& Jufan, 2015).

Mengingat tingginya pemakaian USG saat ini, maka kontrol kualitas terhadap USG wajib dilakukan guna mengendalikan kualitas output yang dihasilkan. Hasil yang diperoleh kemudian dibandingkan dengan standard yang ada (Nugraheny, 2015). Pengendalian ini dilakukan untuk menjamin kegiatan operasi yang dilakukan sesuai dengan yang direncanakan sehingga terjadi penyimpangan bisa dikoreksi agar apa yang diharapkan bisa tercapai (Amitasari, Adi, Fisika, \& Diponegoro, 2015).

Beberapa literatur menunjukkan bahwa kualitas citra USG biasanya diukur dengan menggunakan parameter QC USG antara lain: pemeriksaan fisik, keseragaman citra, kedalaman visualisasi, akurasi jarak vertikal dan horizontal, persepsi objek anechoic, resolusi spasial (resolusi aksial dan resolusi lateral) dan dead zone (Fallo \& Adi, 2014). Dalam penelitian ini akan dibahas parameter uji control USG yaitu uji akurasi jarak dan resolusi aksial menggunakan media phantom silicone. Phantom silicone memiliki beberapa kelebihan dibandingkan phantom yang berbahan dasar gelatin ataupun agar-agar diantaranya dapat dibentuk sesuai kebutuhan, tahan lama dan dapat digunakan kembali. Perancangan dan implementasi penelitian ini menggunakan software pengolahan citra digital (Kurniawan, n.d.). 


\section{METODE PENELITIAN}

Penelitian ini diawali dengan membuat phantom silicone. Desain phantom silicone ditunjukkan pada Gambar 1.

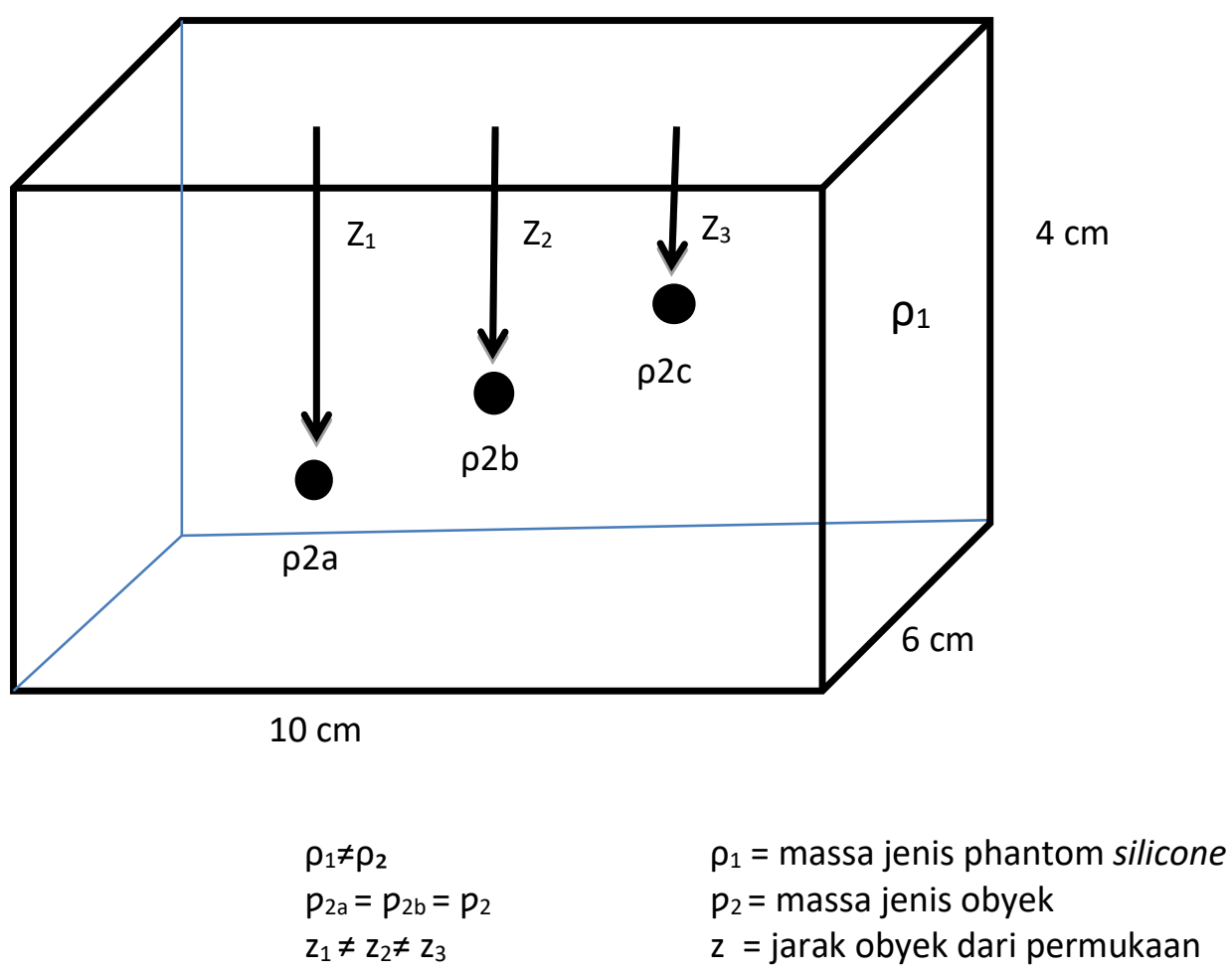

Gambar 1. Desain silicone rubber phantom ultrasound.

Phantom dibuat dengan bahan dasar silikon rubber TV (Room Temperature Vulcanitation) tipe 48. Katalis dengan konsentrasi $0,8 \%$ dan cetakan yang digunakan berbahan plastik dengan bentuk balok dengan ukuran $(p \times / \times t) \mathrm{cm}$ adalah $(10 \times 6 \times 4 \mathrm{~cm})$. Hasil dari uji coba yang dilakukan didapatkan konsentrasi campuran silicone dan katalis yang paling sesuai untuk penelitian ini sebesar $0,8 \%$. Objek yang digunakan dalam penelitian ini adalah bola besi pejal sebanyak 3 buah dengan diameter $0,2 \mathrm{~cm}$. Objek disusun dalam wadah cetakan dengan cara ditopang menggunakan kayu yang sudah dibentuk menyerupai batang korek api dengan ketinggian berbeda yaitu $1 \mathrm{~cm} ; 2 \mathrm{~cm}$; dan $3 \mathrm{~cm}$. Wadah lain digunakan untuk pencampuran silikon dan katalis, adonan yang yang sudah tercampur dituang kedalam cetakan yang sudah terpasang objek hingga penuh. Gelembung udara yang nampak pada permukaan saat penuangan adonan harus dipecahkan supaya tidak mempengaruhi saat proses pemindaian dilakukan, setelah itu phantom didiamkan kurang lebih 1 bulan agar mengeras. Kemudian phantom tersebut dipindai menggunakan USG merk Mindray model DP-10. Hasil pemindaian dilakukan seperti Gambar 2.

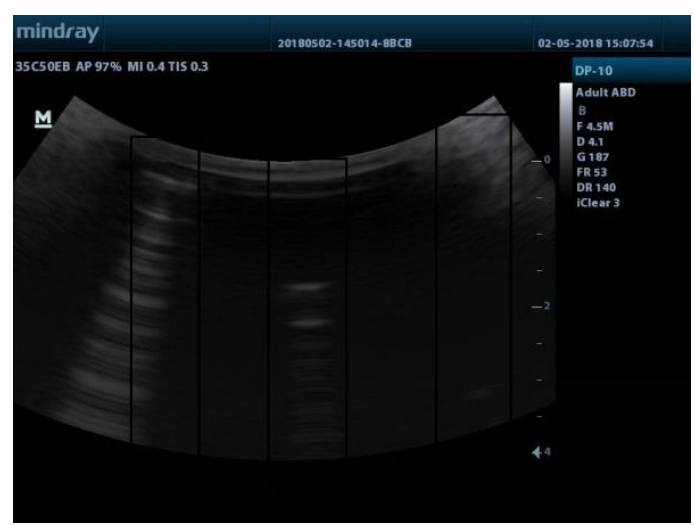

Gambar 2. Citra hasil scan phantom dengan area per objek.

Phantom memiliki 3 titik pindai dimana setiap titiknya memiliki jarak dari permukaan yang sudah diatur sebelumnya, setiap titik dilakukan pemindaian sebanyak 2 kali dengan mengubah frekuensi yaitu 
dengan frekuensi $3.5 \mathrm{MHz}, 4.5 \mathrm{MHz}$ sehingga terdapat 6 hasil pemindaian. Batas pemindaian disesuaikan dengan lebar probe USG, saat melakukan pemindaian USG diletakkan tepat diatas permukan sejajar dengan objek. Karena citra berbentuk curve tidak kotak simetris di mana bagian tengah dan samping memiliki luasan yang berbeda maka jarak bisa dihitung menggunakan persamaan berikut ini (Maslebu, Adi, \& Suryono, 2015):

$$
\begin{aligned}
& \text { resolusi spasial }=\frac{j u m l a h p i k s e l(p i k s e l]}{j a r a k(\mathrm{~cm})} \\
& \text { jarak sebenarnya }=\frac{j u m l a h \text { piksel }}{\text { resolusi spasial }} . . . . . . . .
\end{aligned}
$$

\section{HASIL DAN PEMBAHASAN}

Hasil citra dari pengujian QC pesawat USG digunakan untuk menghitung jarak dengan variasi nilai frekuensi $(\mathrm{MHz})$ dan depth (kedalaman). Kemudian citra dianalisis dengan menggunakan komputasi software pengolah citra. Analisis akurasi jarak ini dilakukan dengan menggunakan software pengolah citra digital untuk melihat kualitas citra pada USG.

Setelah dilakukan perhitungan didapatkan nilai resolusi spasial pada masing masing citra. Resolusi spasial merupakan ukuran objek terkecil yang masih dapat dibedakan dan dikenali pada citra (Supriyatin \& Rafsyam, 2015). Resolusi USG akan semakin baik apabila gelombang suara dan frekuensi semakin besar (Nugraheny, 2015). Dengan demikian maka semakin padat medium tersebut nilai kecepataan suara juga akan semakin besar (Sudarsih, Budi, \& Suryono, 2014). Ketika frekuensi semakin tinggi maka semakin banyak energi yang diserap, sehingga semakin sedikit energi yang diteruskan (Syafrudin, Suryono, \& Suseno, 2008). Gelombang suara melalui dua medium dengan massa jenis ( $\rho$ ) yang berbeda maka sebagian gema (echo) akan diteruskan dan sebagian lagi akan dipantulkan. Besar gema yang dipantulkan tergantung dari impendansi akustik medium. Impendansi akustik (Z) adalah kemampuan untuk melewatkan gelombang yang melaluinya (Darmajaya, 2017).

Dalam penelitian ini resolusi spasial sebagai indikator jumlah piksel per satuan panjang $(1 \mathrm{~cm})$. Penentuan resolusi spasial dilakukan dengan menghitung jumlah piksel yang ada diantara pusat dari dua objek terdekat (Maslebu et al., 2015). Resolusi spasial ditunjukkan pada Tabel 1.

Tabel 1. Nilai resolusi spasial berdasarkan nilai frekuensi

\begin{tabular}{|c|c|}
\hline Frekuensi (MHz) & Resolusi spasial $(\mathrm{cm})$ \\
\hline 3.5 & 43.0299 \\
\hline 4.5 & 42.8972 \\
\hline
\end{tabular}

Dari hasil perhitungan resolusi spasial yang disajikan pada Tabel 1 didapatkan nilai konstan ratarata sebesar 43,1445 pixel/cm. Setiap objek dihitung sebanyak 30 kali dan salah satu contoh hasil perhitungan ditampilkan pada Gambar 3-8.
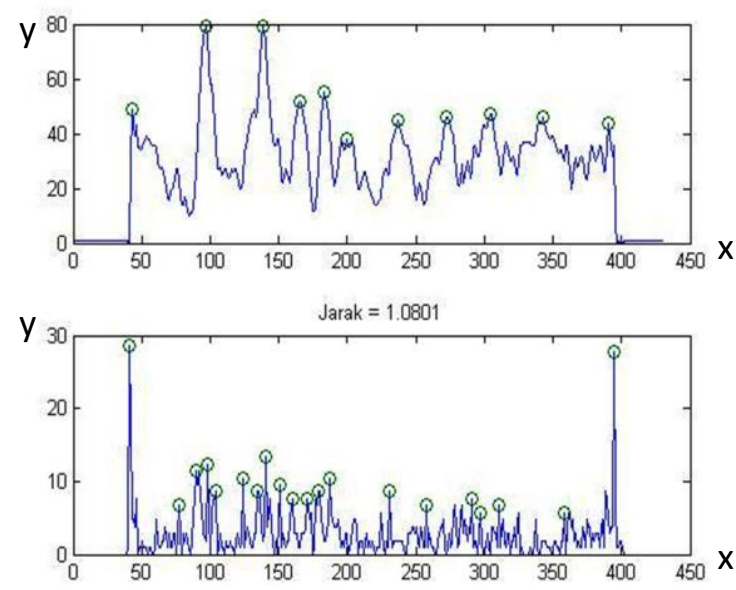

Gambar 3. Grafik yang menunjukkan nilai sebenarnya objek 1 pada frekuensi 3.5 $\mathrm{MHz}$.
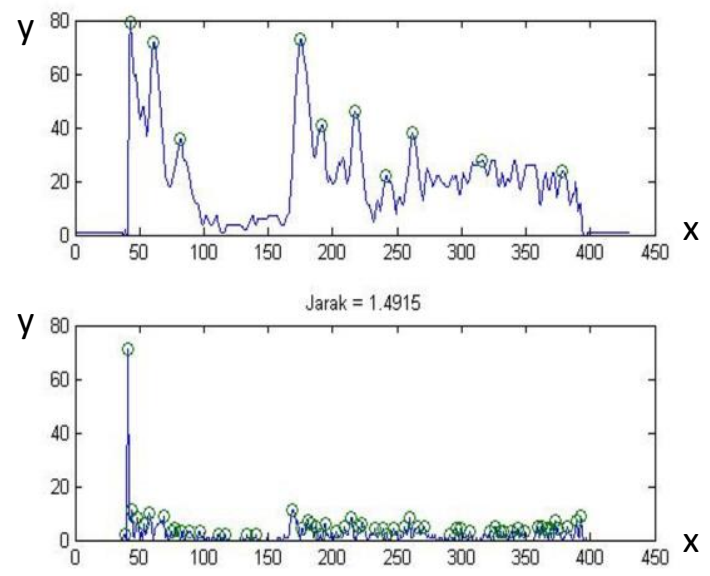

Gambar 4. Grafik yang menunjukkan nilai sebenarnya objek 2 pada frekuensi 3.5 $\mathrm{MHz}$. 

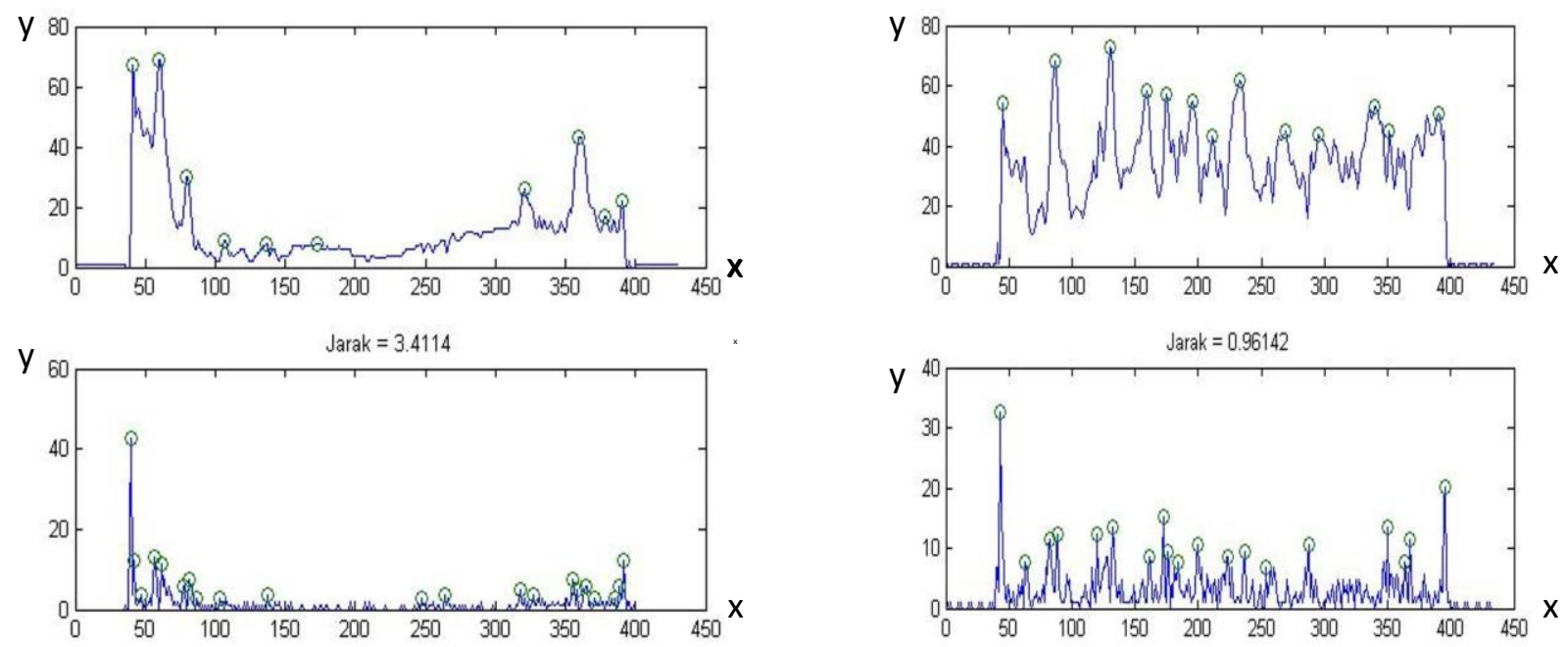

Gambar 5. Grafik yang menunjukkan nilai sebenarnya objek 3 pada frekuensi 3.5 $\mathrm{MHz}$.

Gambar 6. Grafik yang menunjukkan nilai sebenarnya objek 1 pada frekuensi 4.5 $\mathrm{MHz}$.
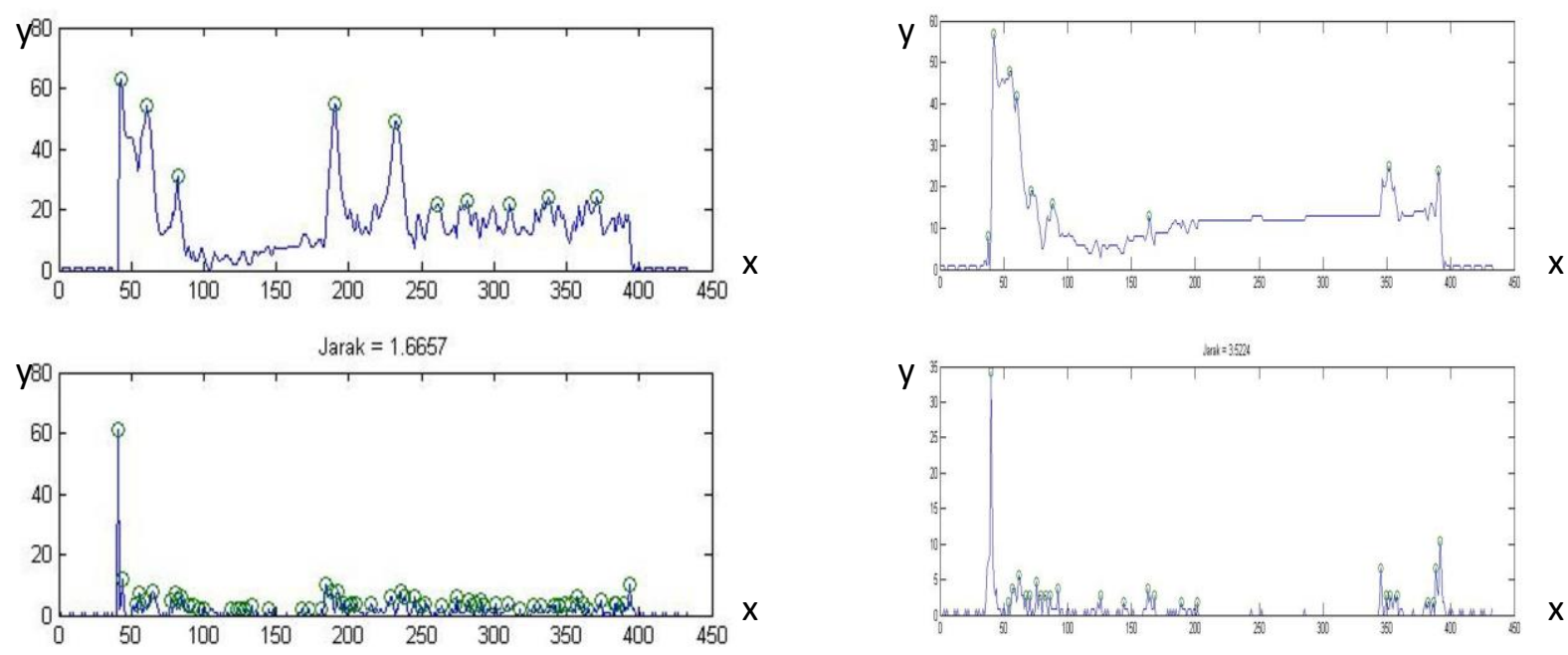

Gambar 7. Grafik yang menunjukkan nilai sebenarnya objek 2 pada frekuensi 4.5 $\mathrm{MHz}$.

Gambar 8. Grafik yang menunjukkan nilai sebenarnya objek 3 pada frekuensi $4.5 \mathrm{MHz}$.

Gambar 3-8 menunjukkan nilai sebenarnya yang dihasilkan dari perhitungan komputasi. Resolusi axial berlaku untuk arah radial dan perubahan frekuensi berdampak pada perubahan kedalaman visualisasi maksimum. Dari grafik diatas menunjukkan ketika frekuensi meningkat, nilai maksimum kedalaman visualisasi akan cenderung sedikit berubah akan tetapi nilainya masih relatif sama atau stabil. Pada frekuensi 3,5 MHz, jarak rata-rata komputasi maksimum pada objek 1, 2, dan 3 berturut turut sebesar $1,0801 \mathrm{~cm} ; 1,4915 \mathrm{~cm}$; dan 3,4114 cm. Pada frekuensi tetap 4,5 MHz, kedalaman visualisasi maksimum pada objek 1, 2, dan 3 berturut turut sebesar 0,9614 cm; 1,6657 cm; dan 3,5224 cam.

Hasil yang disajikan pada Gambar 3-8 merupakan salah satu dari perhitungan yang diperoleh dari perhitungan jarak sebenarnya. Dari hasil perhitungan sebanyak 30 kali dengan mengubah frekuensi diperoleh nilai yang berbeda atau menyimpang dari nilai jarak sebenarnya sehingga dapat dihitung standard deviasi untuk nilai tersebut. Berdasarkan hasil jarak sebenarnya yang didapatkan dari perhitungan komputasi dapat dihitung nilai standard deviasi. Nilai besarnya kesalahan (error) bisa dihitung mengunakan rumus berikut:

$$
\% \text { error }=\frac{\text { nilai jarak sebenarnya-nilai ratarata jarak hitungan komputasi }}{\text { nilai jarak sebenarnya }} \times 100 \%
$$


Jurnal Sains dan Edukasi Sains, Vol.2, No.1, Februari 2019: 36-41

Dari perhitungan yang sudah dilakukan didapatkan hasil yang ditunjukkan pada Tabel 2 berikut:

Tabel 2. Nilai standard deviasi untuk masing masing objek pada frekuensi 3,5 $\mathrm{MHz}$ dan 4,5 MHz

\begin{tabular}{|c|c|c|c|c|c|c|c|}
\hline \multirow{2}{*}{ Objek } & \multirow{2}{*}{ Jarak sebenarnya $(\mathrm{cm})$} & \multicolumn{2}{|c|}{ Rata-rata Jarak hasil komputasi (cm) } & \multicolumn{2}{|c|}{ Standar deviasi } & \multicolumn{2}{c|}{ \%kesalahan (error) } \\
\cline { 3 - 8 } & & $3,5 \mathrm{MHz}$ & $4,5 \mathrm{MHz}$ & $3,5 \mathrm{MHz}$ & $4,5 \mathrm{MHz}$ & $3,5 \mathrm{MHz}$ & $4,5 \mathrm{MHz}$ \\
\hline 1 & 1 & 1,0039 & 0,9931 & 0,0814 & 0,05 & 0,39 & 0,69 \\
\hline 2 & 2 & 1,4897 & 1,6584 & 0,0099 & 0,0573 & 25,51 & 17,08 \\
\hline 3 & 3 & 3,3336 & 3,4943 & 0,1191 & 0,0741 & 11,12 & 16,47 \\
\hline
\end{tabular}

Tabel 2 menunjukkan jarak rata-rata komputasi masing-masing obyek yang dihitung sebanyak 30 kali yang kemudian dihitung standar deviasi dan \% kesalahannya terhadap nilai jarak sebenarnya. Pada frekuensi 3,5 MHz, nilai kedalaman rata-rata visualisasi untuk objek 1 adalah 1,0039 cm dengan nilai deviasi sebesar 0,0814 sehingga nilai kesalahan jarak pada objek 1 yang memiliki nilai jarak sebenarnya $1 \mathrm{~cm}$ adalah $0,39 \%$.

Tabel tersebut menunjukkan bahwa nilai jarak sebenarnya yang dihitung dengan teknik komputasi yang dilakukan sebanyak 30 kali untuk masing masing objek dengan merubah frekuensi mengalami nilai yang berbeda beda dan menyimpang dari nilai jarak sebenarnnya. Penyimpangan atau nilai error bisa disebabkan karena kemampuan komputasi memilih peak (puncak) intensitas. Grafik hasil komputasi menunjukkan terdapat banyak titik intensitas sehingga didapatkan nilai kesalahan. Didapatkan nilai kesalahan tinggi dikarenakan belum tepatnya pengambilan data puncak intensitas objek terhadap permukaan.

\section{KESIMPULAN}

Hasil penelitian yang dilakukan menunjukkan perhitungan jarak pada citra pesawat USG bisa dilakukan dengan menggunakan perangkat lunak computer. Dari analisis yang dilakukan melalui program komputasi dapat diketahui bahwa jarak hasil komputasi citra USG dalam perhitungan dipengaruhi oleh nilai kedalaman dan ketepatan dalam pemilihan puncak grafik intensitas.

\section{DAFTAR PUSTAKA}

Amitasari, R., Adi, K., Fisika, J., \& Diponegoro, U. (2015). Pengaruh Gain Terhadap FWHM Dan FWTM Pada Citra B-Mode Ultrasonogram ( USG ), 18(2), 59-66.

Darmajaya, S. I. I. B. (2017). Desain Aplikasi Pengolahan Citra Untuk Data, 232-241.

Fallo, F., \& Adi, K. (2014). Perancangan Model Pengukuran Jarak Menggunakan Computer-Aided Pada, $17(1), 13-20$.

Kurniawan, H. (n.d.). Perancangan Program Pengenalan Wajah Menggunakan Fungsi Jarak Metode Euclidean Pada Matlab.

Maslebu, G., Adi, K., \& Suryono. (2015). Effect of Gain Changing to Maximum Visualization Depth on Diagnostic Ultrasound B-Mode Image. Journal of Applied Engineering Research, 10(13), 3344933452.

Munawar, N. M. Al, W, C. F., \& Jufan, A. Y. (2015). Peran Ultrasonografi dalam Kegawatdaruratan. JURNAL KOMPLIKASI ANESTESI, 2(2), 85-94.

Nugraheny, D. (2015). Metode Nilai Jarak Guna Kesamaan Atau Kemiripan Ciri Suatu Citra (Kasus Deteksi Awan Cumulonimbus Menggunakan Principal Component Analysis). JURNAL ANGKASA, 7(2), 21-30.

Sudarsih, K., Budi, W. S., \& Suryono. (2014). Analisis Keseragaman Citra Pada Pesawat UltrasonograFI (USG). Berkala Fisika, 17(1), 33-38.

Supriyatin, W., \& Rafsyam, Y. (2015). Aplikasi Penajaman Citra Grayscale Menggunakan Metode Gauss. 
ORBITH, 11(1), 30-35.

Syafrudin, A., Suryono, \& Suseno, J. E. (2008). Rancang Bangun Generator Pulsa Gelombang Ultrasonik dan Implementasinya untuk Pengukuran Jarak Antara Dua Obyek. Berkala Fisika, 11(2), 29-37. 